\title{
Surface and Catalytical effects on Treated Carbon Materials for Hydrogen Peroxide Electrogeneration
}

\author{
A. Moraes ${ }^{1}$ - M. H. M. T. Assumpção ${ }^{1}$ F. C. Simões ${ }^{1}$ - V. S. Antonin ${ }^{1}$ - M. R. V. Lanza ${ }^{2}$ \\ P. Hammer ${ }^{3}$ - M. C. Santos ${ }^{1}$
}

Published online: 28 September 2015

(C) Springer Science+Business Media New York 2015

\begin{abstract}
This work focuses on the catalytic activity and surface modification of Vulcan XC 72R and Printex L6 toward the oxygen reduction reaction (ORR) after the carbon supports were subjected to a pre-treatment with nitric acid or ammonia. The results indicated that acid-treated Printex L6 was the bestsuited material toward the two-electron pathway of the ORR. This material contained the largest concentration of oxygenated acid species and hydrogen, as determined by XPS, the Boehm method, and elemental analysis. The enhanced formation of $\mathrm{H}_{2} \mathrm{O}_{2}$ for acid-treated Printex L6 can be explained by the presence of oxygenated acid species increasing the hydrophilic character of the carbon support. The hydrophilicity of the material was investigated by contact angle measurements. However, the changes of the surface area, porosity, and the aliphatic chains of the carbons induced by the pre-treatments and the contributions of these factors to $\mathrm{H}_{2} \mathrm{O}_{2}$ production cannot be disregarded.
\end{abstract}

Keywords Carbon supports · Oxygen reduction reaction $(\mathrm{ORR}) \cdot$ Electrogeneration of hydrogen peroxide

\section{C. Santos}

mauro.santos@ufabc.edu.br

1 LEMN - Laboratório de Eletroquímica e Materiais Nanoestruturados - CCNH -Centro de Ciências Naturais e Humanas, UFABC - Universidade federal do ABC, CEP 09.210-170, Rua Santa Adélia 166, Bairro Bangu, Santo André, SP, Brazil

2 Instituto de Química de São Carlos, Universidade de São Paulo, Caixa Postal 780, CEP 13.566-590 São Carlos, SP, Brazil

3 Instituto de Química, UNESP, Universidade Estadual Paulista, 14800-060 Araraquara, SP, Brazil

\section{Introduction}

Carbon black is a fascinating material that has attracted worldwide interest because of both its fundamental properties and its applications [1] and because the modification of the surface chemistry of carbons is recognized as an attractive route toward the application of these materials as adsorbents for both gas and liquid phases, as catalysts and as catalyst supports [2].

Activated carbons have some advantages as catalyst supports because they are relatively inexpensive, possess a high surface area, and allow easy recovery of supported metals through simple combustion of the support. All of these features make activated carbons attractive or even indispensable as supports in many cases [3].

A variety of oxidative treatments have been developed to produce acid-activated carbons with distributions of oxygencontaining groups [4-7], and thermal treatment in different gaseous environments or basic treatments have been used to obtain carbons with low oxygen content, basic properties, and hydrophobic character [7-10].

Moreover, the nature of the carbon surface and the presence of functional groups are known to strongly influence the properties of carbon-supported metal catalysts [11]. The functionalities present on the carbon surface in the form of surface oxides (e.g., carboxylic groups, phenolic groups, lactic groups, etheric groups, and others) are responsible for the acid/base and the redox properties of the carbons [7].

Some authors [4, 11] have affirmed that the acid surface oxide may play an especially important role in adsorption and catalysis and that good dispersion and resistance to sintering are related to the number of surface oxygen groups present on the carbon surface. However, other authors have shown that the presence of oxygen surface groups on carbon decreases the metal dispersion and that the electroactivity of some catalysts 
is enhanced by the carbon supports with basic or neutral agents [7].

With respect to the $\mathrm{H}_{2} \mathrm{O}_{2}$ electrogeneration via the oxygen reduction reaction (ORR), carbon is a well-known cathode material for the two-electron reduction of oxygen to hydrogen peroxide in an alkaline solution [12-14] and is the best choice for an electrocatalyst because of its large specific surface area, strong corrosion resistance, and low cost [15].

Assumpção et al. [16] evaluated two different carbon supports (without pre-treatment) toward the ORR, authors observed that the best $\mathrm{H}_{2} \mathrm{O}_{2}$ electrogeneration was obtained with the carbon support that contained the highest surface oxygen content. In addition, Marcotte et al. [17], who used a cobalt electrocatalyst supported on a carbon with enriched surface nitrogen, showed that the $\mathrm{H}_{2} \mathrm{O}_{2}$ percentage decreased with increasing nitrogen content on the catalyst surface. According to these results, oxygen enriched surface results in the best electroactivity toward the two-electron transfer during the electrogeneration of $\mathrm{H}_{2} \mathrm{O}_{2}$ via the $\mathrm{ORR}$.

In order to obtain more information on the better suited carbon surface for the electrogeneration of $\mathrm{H}_{2} \mathrm{O}_{2}$, considering that Printex L6 and Vulcan XC 72R are the most promising materials for use as active supports, we have conducted a systematic comparison of the chemical and electrochemical properties of these two types of carbons with different pretreatments (acidic and basic) for the in situ electrogeneration of hydrogen peroxide. The goal of the carbon modification by acid and basic treatment was to obtain a more hydrophilic surface structure with a relatively large number of oxygencontaining groups that exhibit ion-exchange properties [18].

\section{Experimental}

\section{Carbon Materials}

The carbon materials, Vulcan XC 72R and Printex L6, were purchased from Cabot Corporation and Degussa, respectively, and were treated using two different processes: (1) acidic process, $1 \mathrm{~g}$ of the carbon materials was used which was treated with approximately $30 \mathrm{~mL}$ of nitric acid $(70 \%)$ (Synth) under stirring for $4 \mathrm{~h}$ at $60{ }^{\circ} \mathrm{C}$, and (2) an alkaline process, in which $1 \mathrm{~g}$ of the carbons was treated with approximately $30 \mathrm{~mL}$ of ammonium hydroxide $(25 \%)$ under stirring for $4 \mathrm{~h}$ at $60{ }^{\circ} \mathrm{C}$. After the treatment, all the materials were washed with distilled water until the $\mathrm{pH}$ was 7 , and they were then placed in a desiccator for $24 \mathrm{~h}$. For comparison, a commercial catalyst of $20 \mathrm{wt} \%$ platinum supported on Vulcan XC 72R and not subjected to an acid or base treatment $(\mathrm{Pt} / \mathrm{C} \mathrm{E}$ TEK) was used as a reference material for four-electron transference in the ORR.

\section{Support Characterization}

Elemental Analysis, Scanning Electron Microscopy Images, BET Surface Area and X-ray Photoelectron Spectroscopy

To compare all of the carbon materials used in this work, elemental analyses using a Perkin-Elmer CHN 2400 analyzer were performed to obtain the carbon, hydrogen and nitrogen percentages of the samples. The oxygen loads were also obtained from these results by subtraction of the other element percentages. Thus, Scanning Electron Microscopy (SEM) measurements were carried out using a JEOL JSM-6010 LA operated at $15 \mathrm{kV}$ in order to analyses changes of the surface. Brunauer, Emmett, and Teller (BET) surface area was conducted using an ASAP 2000 equipment from micrometrics. The XPS analysis was carried out at a pressure of less than $10^{-7} \mathrm{~Pa}$ using a commercial spectrometer (UNI-SPECS UHV System). The Mg Kalpha line was used $(\mathrm{hv}=1253.6 \mathrm{eV})$ and the analyzer pass energy was set to $10 \mathrm{eV}$. The inelastic background of the $\mathrm{C} 1 \mathrm{~s}$ and $\mathrm{O} 1 \mathrm{~s}$ electron core-level spectra was subtracted using Shirley's method. The composition (at.\%) of the near surface region was determined with an accuracy of $\pm 10 \%$ from the ratio of the relative peak areas corrected by Scofield's sensitivity factors of the corresponding elements. The spectra were fitted without placing constraints using multiple Voigt profiles.

\section{Functional Group Analysis by the Boehm Methodology}

After the carbon supports were treated using the different processes, the concentrations of acidic and basic surface groups on the supports were determined by the Boehm methodology [5, 19-22]. We determined the concentrations of basic sites by weighing $1 \mathrm{~g}$ of each carbon material (Printex L6, acid- and base-treated Printex L6, Vulcan XC 72R, acid- and base-treated Vulcan XC 72R) and placing them in different beakers, all of which contained $50 \mathrm{~mL}$ of $0.1 \mathrm{~mol} \mathrm{~L}^{-1} \mathrm{HCl}$. These solutions were subsequently stirred at room temperature for $24 \mathrm{~h}$. After this period, all the solutions were filtered, and aliquots of $10 \mathrm{~mL}$ of each filtered solution were titrated with a standard solution of $0.1 \mathrm{~mol} \mathrm{~L}^{-1} \mathrm{NaOH}$ to a phenolphthalein end point. The surface functional groups were calculated using the following equation:

$\mathrm{mEq}$ groups $=\frac{V_{\mathrm{T}} N_{\mathrm{b}}\left(V_{\mathrm{b}}-V_{\mathrm{am}}\right)}{V_{\mathrm{al}}}$

where $V_{\mathrm{b}}$ is the volume $(\mathrm{mL})$ of the $\mathrm{NaOH}$ solution added during the titration of the $\mathrm{HCl}$ solution, $V_{\mathrm{am}}$ is the volume $(\mathrm{mL})$ of the $\mathrm{NaOH}$ solution added during the titration of the carbon sample, $V_{\mathrm{T}}$ is the volume $(\mathrm{mL})$ of $\mathrm{HCl}$ used in the adsorption, $V_{\mathrm{al}}$ is the volume $(\mathrm{mL})$ of the filtered aliquot used for the titration, and $N_{\mathrm{b}}$ is the $\mathrm{NaOH}$ concentration in Eq. 1.

For the determination of the acid surface groups, three samples of $1 \mathrm{~g}$ of each treated and untreated carbon were 
weighed and placed in different beakers that contained $50 \mathrm{~mL}$ of standard $0.1-\mathrm{N}$ solutions of sodium hydroxide, sodium bicarbonate, or sodium carbonate. Similar to the determination of basic groups, all of the solutions were stirred at room temperature for $24 \mathrm{~h}$; after this period, all the solutions were filtered, and aliquots of $10 \mathrm{~mL}$ of the filtered solutions were titrated with a standard solution of $0.1 \mathrm{~mol} \mathrm{~L}^{-1} \mathrm{HCl}$ to a phenolphthalein end point. In the case of the sodium bicarbonate and sodium carbonate solutions, 15 and $20 \mathrm{~mL}$ of $0.1 \mathrm{~mol} \mathrm{~L}^{-1}$ $\mathrm{HCl}$ were added, respectively, to the $10-\mathrm{mL}$ aliquots of the filtered samples, which were subsequently back titrated with a standard solution of $0.1 \mathrm{~mol} \mathrm{~L}^{-1} \mathrm{NaOH}$. In these cases, the solutions were first boiled, cooled to room temperature, and then titrated with the standard solution of $\mathrm{NaOH}$ using phenolphthalein as an indicator. The acid surface groups were determined using Eq. 1 after subtracting the $\mathrm{NaOH}$ volume used in the sample titration and the $\mathrm{NaOH}$ volume used in the $\mathrm{HCl}$ titration without the carbon. In this equation, $V_{\mathrm{T}}$ is the volume of $\mathrm{NaHCO}_{3}, \mathrm{Na}_{2} \mathrm{CO}_{3}$, or $\mathrm{NaOH}$ used in each adsorption process $[5,19,23]$.

After the titrations, the concentrations of carboxylic surface groups were obtained using Eq. 1 and the results of the titration of the sodium bicarbonate solution. The concentrations of lactic surface groups were determined by the difference between the results of the titrations of the sodium carbonate and sodium bicarbonate solutions. The concentrations of phenolic surface groups were obtained by the difference between the concentrations of groups determined by the $\mathrm{NaOH}$ titration and by the sodium carbonate titration.

\section{Electrochemical Characterization}

Electrochemical measurements were performed with an Autolab PGSTAT $302 \mathrm{~N}$ potentiostat/galvanostat using a rotating-disk electrode system from Pine Instruments that consisted of a glassy carbon disk (area $=0.2475 \mathrm{~cm}^{2}$ ) and an Au ring $\left(\right.$ area $\left.=0.1866 \mathrm{~cm}^{2}\right)$. The collection efficiency $(\mathrm{N})$ was constant for all measurements and was equal to 0.37 .

For the electrochemical studies, a three-electrode conventional cell was employed. The reference electrode and counter electrode were $\mathrm{Hg} / \mathrm{HgO}\left(\mathrm{NaOH} 4 \mathrm{~mol} \mathrm{~L}^{-1}\right.$ ) and $\mathrm{Pt}$ (geometric area $=2 \mathrm{~cm}^{2}$ ), respectively. As the working electrode, an ink of the carbon materials was prepared as described by Paulus et al. [24]: $5 \mathrm{mg}$ of the powder was dispersed in $5 \mathrm{~mL}$ of water and mixed for $60 \mathrm{~min}$ in an ultrasonic bath. Afterwards, $20 \mu \mathrm{L}$ aliquots of the carbon dispersion were pipetted onto carbon disk (resulting in a total load of $0.81 \mu \mathrm{g} \mathrm{cm}^{-2}$ ), and after the water was evaporated under a nitrogen stream, $20 \mu \mathrm{L}$ of a diluted Nafion ${ }^{\circledR}$ solution (5 wt $\%$, Fluka) was dropped onto the glassy carbon surface to attach the catalyst particles. The $\mathrm{H}_{2} \mathrm{O} / \mathrm{Nafion}^{\circledR}$ ratio in the solution was ca. 100 :1.

The ORR was studied in a $1 \mathrm{~mol} \mathrm{~L}^{-1} \mathrm{NaOH}$ solution using a rotating ring-disk electrode technique. This technique is used to study the extent to which each of the pathways ( 2 or 4 electron transferences) is involved at a particular electrode surface. By this technique, the ring is used to oxidize the peroxide produced on the disk electrode by the reduction of the oxygen $[25,26]$.

The electrolyte solution was first deoxygenated by nitrogen gas bubbling for approximately $20 \mathrm{~min}$ and was subsequently saturated with oxygen for approximately $40 \mathrm{~min}$, maintaining the oxygen flow over the electrolyte during the entire analysis of the ORR. The measurements were repeated for various rotation rates that ranged from 100 to $3600 \mathrm{rpm}$; the scan rate was $5 \mathrm{mV} \mathrm{s}^{-1}$. All measurements were conducted at room temperature.

\section{Contact Angle Measurements}

In this study, a GBXTM digidrop autogoniometer was used to measure the angle between the solid surface and a tangent, drawn on the drop surfaces, passing through the triple-point gas/liquid/solid [27], defined as a contact angle, which is dependent on surface energy, and it characterizes the surface wettability. A contact angle of $\theta<90^{\circ}$ using a drop of pure water means that the surface is hydrophilic and a contact angle of $\theta>90^{\circ}$ represents a hydrophobic surface.

A dispersion of $5 \mathrm{mg}$ of the carbon powder (synthesized as described in "Carbon Materials" section) was prepared in $5 \mathrm{~mL}$ of water and mixed for $60 \mathrm{~min}$ in an ultrasonic bath. Posteriorly, $50 \mu \mathrm{L}$ aliquots of the carbon dispersion were pipetted onto a glassy carbon plate and dried with a nitrogen flow, producing a thin layer used as a substrate. For the contact angle measurement purpose, a drop of $5 \mu \mathrm{L}$ of pure water was added up to the carbon substrate by means of a pipet.

An image analysis system calculated the contour of the drop from an image captured by means of a video camera. Five measurements of contact angle were taken for each of three drops per carbon powder. Each measurement was performed over $5 \mathrm{~min}$ and the averages were calculated, as well as the standard deviation.

\section{Results and Discussion}

\section{Elemental Analysis, Scanning Electron Microscopy Images, and BET Surface Area}

Elemental analysis was performed to obtain the percentage of each element before and after acid and basic treatment of the carbon supports. The results in Table 1 show that the materials were modified by the different treatments. However, the carbons were modified to a greater extent during the acid treatments than during the alkaline treatments. For all of the materials studied, a decrease in the carbon percentages and an increase in the oxygen content were observed. This result was 
Table 1 Elemental analysis results for the treated carbon supports

\begin{tabular}{lllll}
\hline Carbon support & $\% \mathrm{C}$ & $\% \mathrm{H}$ & $\% \mathrm{~N}$ & $\% \mathrm{O}$ \\
\hline Printex & $92.50 \pm 0.11$ & $0.31 \pm 0.08$ & $0.21 \pm 0.03$ & $6.99 \pm 0.16$ \\
Printex A & $52.36 \pm 0.05$ & $1.39 \pm 0.11$ & $0.48 \pm 0.05$ & $45.78 \pm 0.06$ \\
Printex B & $82.47 \pm 0.54$ & $1.11 \pm 0.57$ & $0.22 \pm 0.01$ & $16.20 \pm 0.04$ \\
Vulcan & $97.18 \pm 0.24$ & $0.03 \pm 0.03$ & $0.16 \pm 0.01$ & $2.63 \pm 0.28$ \\
Vulcan A & $36.55 \pm 0.16$ & $1.48 \pm 0.13$ & $0.16 \pm 0.01$ & $61.80 \pm 0.29$ \\
Vulcan B & $48.55 \pm 0.31$ & $5.35 \pm 0.09$ & $0.11 \pm 0.25$ & $45.98 \pm 0.25$
\end{tabular}

$A$ acid-treated, $B$ base-treated, $C$ carbon, $H$ hydrogen, $N$ nitrogen, $O$ oxygen (by difference)

expected because the chemical treatments oxidize the aromatic carbon structure, thereby increasing the oxygen content [28]. The acid treatment resulted in a stronger surface modification, favoring the formation of a larger amount of oxygenated groups [23, 29]. A higher concentration of oxygenated groups favors the formation of a more hydrophilic surface [30], which, in turn, could result in high catalytic activities toward the two-electron transference in the ORR, as already reported in $[16,31]$.

With respect to the results of the elemental analysis, it should be noted that both treatments increased the hydrogen content of the supports, especially in the cases of Vulcan XC $72 \mathrm{R}$ subjected to the alkaline treatment, which exhibited the highest percentage of hydrogen, and the Vulcan and Printex carbons subjected to acid treatments. The hydrogen contained on the carbon surfaces could also improve the $\mathrm{H}_{2} \mathrm{O}_{2}$ production due to the formation of hydrogen bonds with water in the solution, thereby increasing the hydrophilic character of the material $[32,33]$.

With respect to the content of nitrogen in the supports treated with ammonia, no substantial improvement was observed, which can be explained by the fact that the groups that react with $\mathrm{NH}_{3}$ to form basic surface groups are thought to decompose at lower temperatures, thereby yielding predominantly $\mathrm{CO}_{2}$ [18]. Furthermore, the incorporation of nitrogen by a $\mathrm{NH}_{3}$ treatment was only achieved with treatments performed at approximately $700{ }^{\circ} \mathrm{C}[18,34]$. Nitrogen was also identified by elemental analysis of the acid-treated materials and is most likely associated with nitrate ions lodged into the pores of the oxidized carbons, as identified by Chingombe et al. [35].

Considering SEM images (Fig. 1), it is possible to affirm that acid treatments really resulted in a stronger surface modification. According to the literature [16], the Printex L6 BET surface area is $265 \mathrm{~m}^{2} \mathrm{~g}^{-1}$ while Vulcan XC 72R shows a BET surface area of $250 \mathrm{~m}^{2} \mathrm{~g}^{-1}$. Experiments considering Printex with acid treatment showed a BET surface area of $294 \mathrm{~m}^{2} \mathrm{~g}^{-1}$. This value confirms the result obtained with SEM images since the material with acid treatments shows a higher surface area than the others.

\section{Quantitative XPS Analysis}

Table 2 shows the atomic percentage of carbon, oxygen, and nitrogen of untreated and base- and acid-treated Printex L6 and Vulcan XC materials, derived from the high-resolution XPS spectra. As recently reported [16], the untreated Printex L6 material is more oxidized $(7.7$ at.\% O) than Vulcan $\mathrm{XC}$ (2.9 at.\%). As suggested by the results of the elemental analysis, both carbon materials suffer a stronger modification by oxygen groups in the case of acid treatment than base treatment, which is more pronounced for the Printex L6 material. The oxygen concentration of the latter is about 2 at.\% higher than for Vulcan $\mathrm{XC}$ material, reaching up to 21.7 at.\%. The formed functional groups were studied by the XPS bonding state analysis and the Boehm methodology.

\section{Functional Group Analyses by the Boehm Methodology}

The Boehm methodology was employed for the determination of the concentrations of acid and alkaline surface groups; the results are shown in Table 3. They indicate an increase in the concentration of acid groups, primarily the phenolic and lactic acid groups, when Printex L6 was subjected to the acid treatment. The sum of the acid group concentrations in this material was the highest among the investigated materials. In the opposite case, all of the acid group concentrations decreased dramatically in the case of alkaline-treated Printex L6, and the sum of the acid groups was the smallest among the investigated materials. However, the alkaline-treated Printex L6 was also as a good catalyst material for the two-electron pathway in the ORR. In this case, we emphasize that, in addition to the chemical modification of the material surface, acid or alkaline treatment of carbon may modify the physical structure of the substrate, such as its specific surface area and porosity [29, 36, 37], which could also lead to an improvement in the catalytic activity of the material toward the ORR.

With respect to the Vulcan carbon, no substantial modification was observed because the acid and the alkaline treatments resulted in almost equal concentrations of acid and alkaline species. However, as previously mentioned, chemical treatments can also modify the physical structure of the substrate, which can also improve electrocatalytic activity.

A comparison of the elemental analysis and the Boehm methodology results reveals a discrepancy. This discrepancy can be explained by the difficulty of quantitatively neutralizing acid groups localized on polyaromatic rings, which are susceptible to mesomerization and rearrangements [28].

\section{Functional Group Analyses by XPS}

Information on the local bonding structure was obtained by the analysis of the chemical shifts of fitted carbon $\mathrm{C} 1 \mathrm{~s}$ and oxygen O1s high-resolution core-level spectra. The low binding energy 
Fig. 1 SEM images of the different carbons used. Printex with a tool dimension of $100 \mu \mathrm{m}$ for Printex acid treated, Vulcan acid treated, Printex basic treated, and Vulcan basic treated
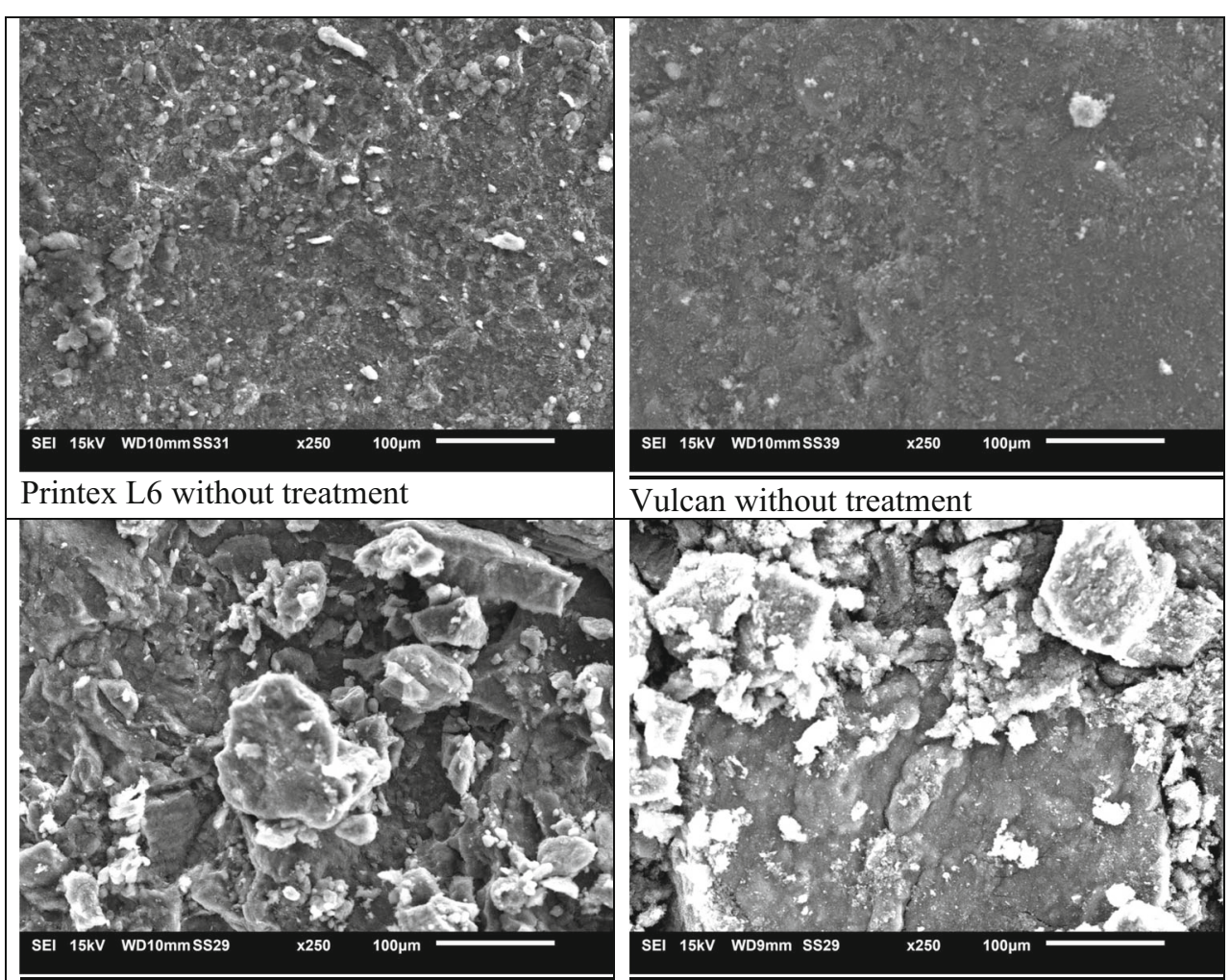

Vulcan without treatment

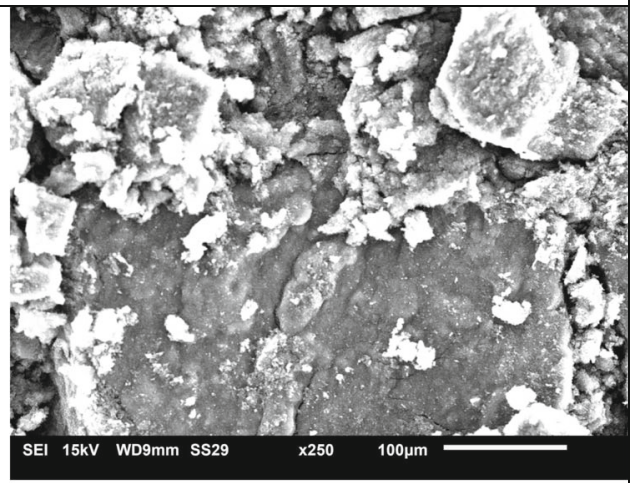

Printex acid treated

Vulcan acid treated

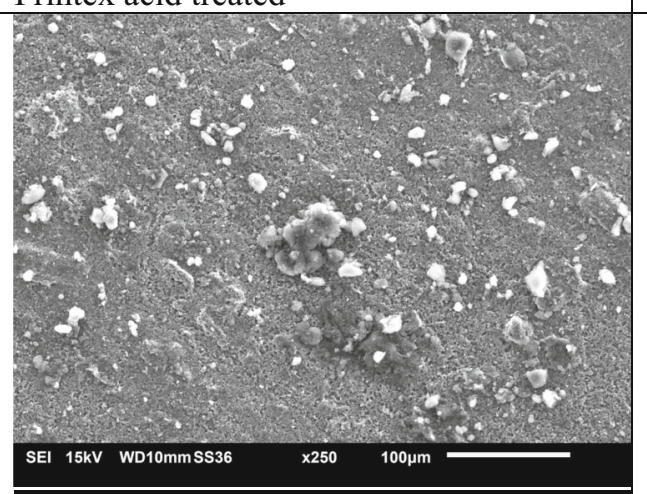

Printex basic treated

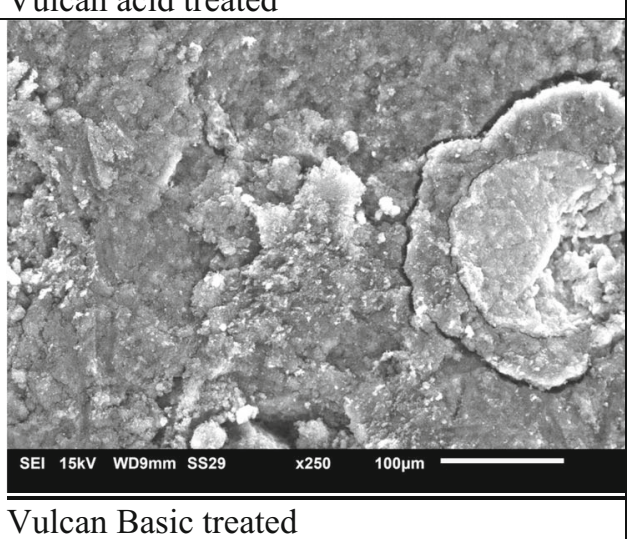

Table 2 Quantitative XPS analysis results for the treated carbon supports

\begin{tabular}{llll}
\hline Carbon support & C at.\% & N at.\% & O at.\% \\
\hline Printex & $92.3 \pm 4.6$ & $>0.2$ & $7.7 \pm 0.4$ \\
Printex A & $78.3 \pm 3.9$ & $>0.2$ & $21.7 \pm 1.1$ \\
Printex B & $79.4 \pm 3.9$ & $0.3 \pm 0.1$ & $20.6 \pm 1.0$ \\
Vulcan & $97.1 \pm 4.8$ & $>0.2$ & $2.9 \pm 0.2$ \\
Vulcan A & $80.6 \pm 4.0$ & $0.3 \pm 0.1$ & $19.4 \pm 1.0$ \\
Vulcan B & $81.3 \pm 4.1$ & $0.3 \pm 0.1$ & $18.7 \pm 0.9$ \\
\hline
\end{tabular}

$A$ acid-treated, $B$ base-treated
Table 3 Concentrations of functional groups on the surfaces of activated carbons $\left(\mathrm{mEq} \mathrm{g}^{-1}\right)$

\begin{tabular}{|c|c|c|c|c|c|}
\hline \multirow[t]{2}{*}{ Carbon } & \multirow[t]{2}{*}{ Alkaline treatment } & \multicolumn{4}{|c|}{ Acid content } \\
\hline & & Carboxylic & Lactic & Phenolic & Total \\
\hline Printex & 0.02 & 0.28 & 0.12 & 0.14 & 0.54 \\
\hline Printex A & 0.00 & 0.26 & 0.16 & 1.09 & 1.51 \\
\hline Printex B & 0.02 & 0.06 & 0.04 & 0.04 & 0.14 \\
\hline Vulcan & 0.10 & 0.13 & 0.63 & 0.40 & 1.16 \\
\hline Vulcan A & 0.00 & 0.06 & 0.62 & 0.40 & 1.02 \\
\hline Vulcan B & 0.04 & 0.06 & 0.61 & 0.34 & 1.07 \\
\hline
\end{tabular}

$A$ acid-treated, $B$ base-treated 
Fig. 2 C1s XPS spectra of untreated and base- and acidtreated carbon materials: a Printex L6 and b Vulcan XC 72R a

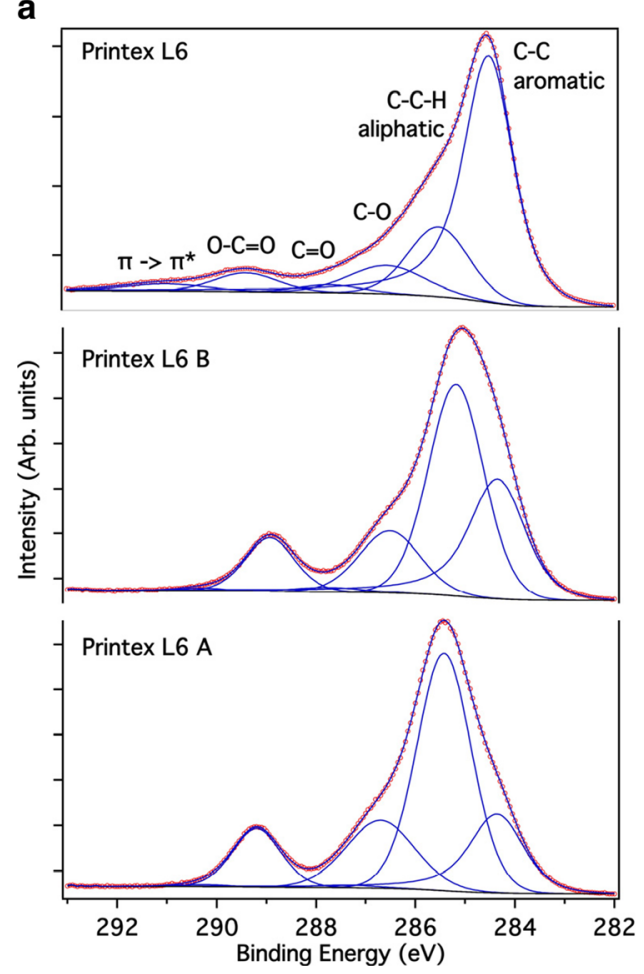

b
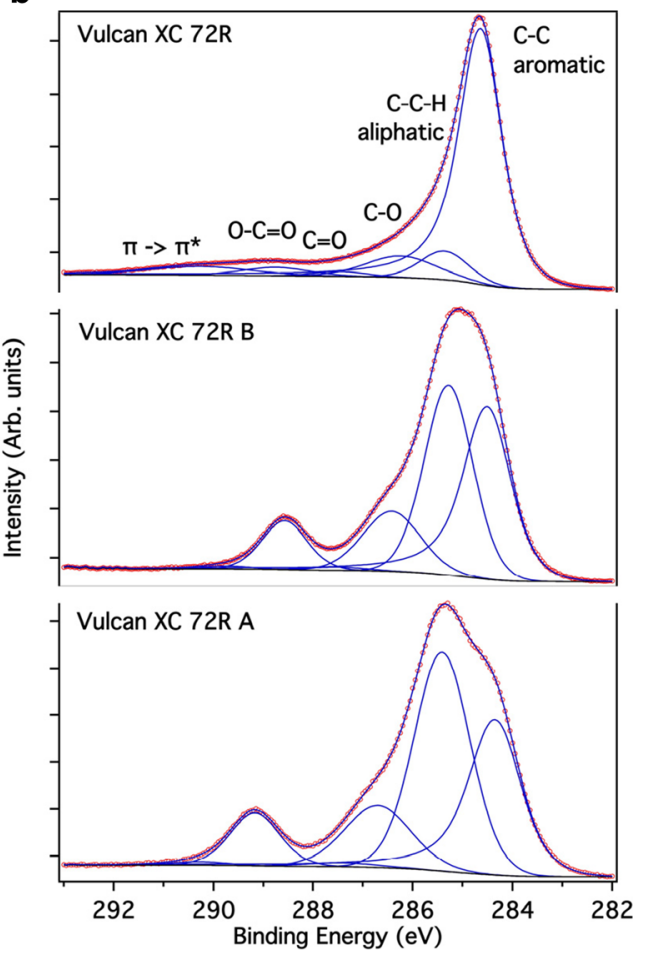

component of the C1s spectra (Fig. 2), located at $284.5 \mathrm{eV}$, is related to graphitic carbon. The sub-peak at about $285.4 \mathrm{eV}$ was assigned to aliphatic hydrocarbons, mostly sp3 C, present in the amorphous structure of the nanoparticulated material, including a partial contribution of surface contamination by adventitious carbon. Although these hydrocarbons include to a small extend also oxidized species, such as $\mathrm{C}-\mathrm{O}, \mathrm{C}=\mathrm{O}$, and carboxylic groups, observed at 286.3, 287.8, and $289.3 \mathrm{eV}$, respectively, the main part of these functional groups is expected to be part of the structure of the carbon materials [38]. Finally, the high binding energy component centered at about $291.0 \mathrm{eV}$ is related to photoemission-induced plasmonic $\pi \rightarrow \pi^{*}$ transitions. Likewise the intensity of the aromatic $\mathrm{C}-\mathrm{C}$ component, the latter is a measure of the degree of aromaticity of the carbon structure.

The deconvoluted O1s core-level spectra are similar for all samples (Fig. 3). Three components, located at 531.8, 532.5, and $533.8 \mathrm{eV}$, are related to $\mathrm{O}=\mathrm{C}, \mathrm{O}-\mathrm{C}$, and $\mathrm{O}-\mathrm{C}=\mathrm{O}$ functional groups, respectively [38]. As expected, the proportions of the fitted intensities scale with those found in the C1s spectra. A small component at about $535 \mathrm{eV}$ was attributed to molecular water present to a larger extent at the surface of untreated carbon materials.

Table 4 displays the relative contribution of each functional group present in the studied carbon materials. As expected, the contribution of the $\mathrm{C}-\mathrm{C}$ aromatic groups and $\pi \rightarrow \pi^{*}$ transitions strongly decreases, while the portion if aliphatic $\mathrm{CC}-\mathrm{H}$ and oxygenated groups increases for both treated materials. As already suggested by the elemental and quantitative XPS analysis, the most pronounced modification by oxygenated groups of the former graphitic phase occurs for the acid-treated Printex L6. Also, in the case of Vulcan XC (Table 3 and Fig. 3b), a slightly enhanced oxidation was found for the acid than for the basic treatment, although less pronounced when compared with Printex L6. It should be noted that for both materials, the functionalization strongly enhances the formation of aliphatic hydrocarbon phase with a more pronounced manner in Printex L6, which explains the obtained results of contact angles, becoming the most abundant phase of the modified material. This finding is in agreement with the detected increase of the hydrogen content of the treated samples (Table 1).

\section{Oxygen Reduction Reaction}

The electrocatalytic activity toward $\mathrm{H}_{2} \mathrm{O}_{2}$ production from the oxygen reduction reaction was evaluated using the ring-disk electrode technique. Figure 4 presents the polarization curves for all of the investigated materials and for the Pt/C E-TEK. As shown in Fig. 4b, the disk current for all carbon materials exhibited the same general shape. However, $\mathrm{Pt} / \mathrm{C}$ exhibited the highest disk current during the ORR when compared with pure carbon materials. In addition, the carbons' disk currents were almost two times lower than that of the $\mathrm{Pt} / \mathrm{C}$; this result was expected because graphite features a two-electron pathway in the ORR and is the reference material for $\mathrm{H}_{2} \mathrm{O}_{2}$ production [18], whereas $\mathrm{Pt} / \mathrm{C}$ is the reference material for the ORR toward four-electron transference, i.e., water production.

As shown in Fig. 4a, the acid-treated Printex L6 exhibited the highest ring current among the materials studied, while Pt/ 
Fig. 3 O1s XPS spectra of untreated and base- and acidtreated carbon materials: a Printex L6 and b Vulcan XC 72
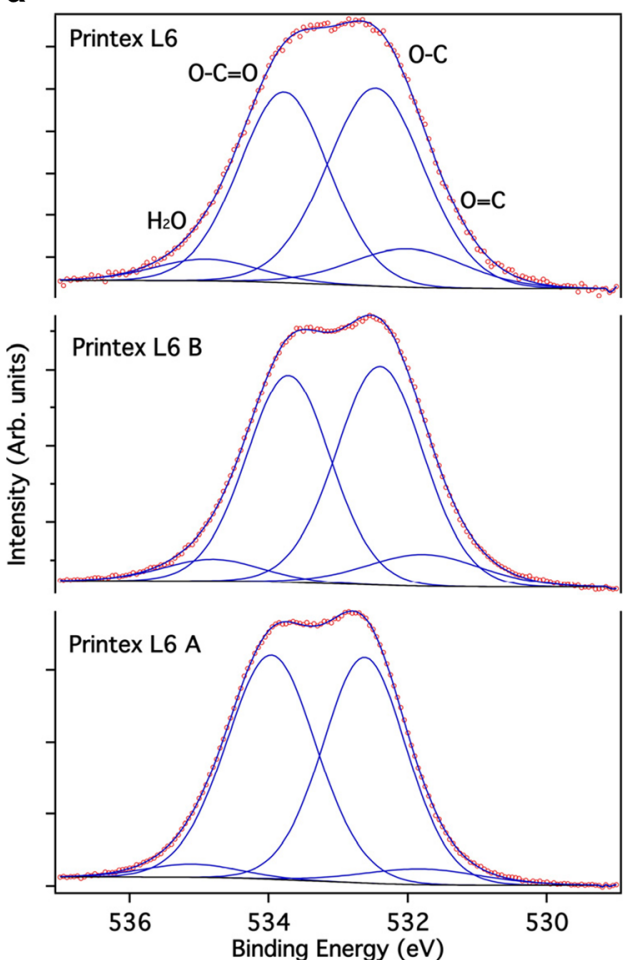

b
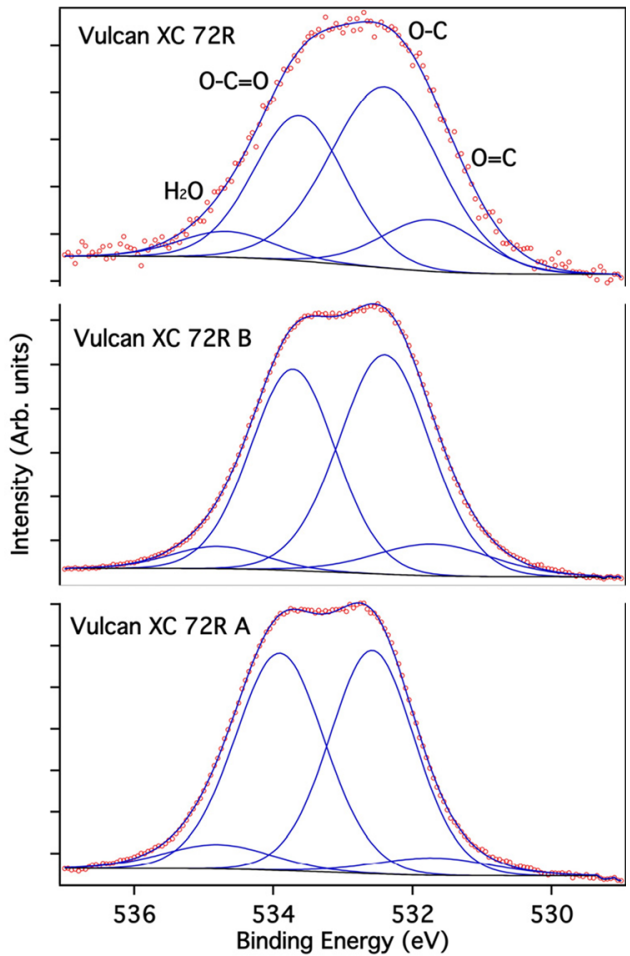

C exhibited the lowest current, as indicated by these materials exhibiting the highest and the lowest production of $\mathrm{H}_{2} \mathrm{O}_{2}$, respectively $[39,40]$. The second-best material for $\mathrm{H}_{2} \mathrm{O}_{2}$ production was the alkaline-treated Printex L6. Given these results and considering that the best material for $\mathrm{H}_{2} \mathrm{O}_{2}$ electrogeneration was the acid-treated Printex L6, we can affirm that the acid-treated carbon, which results in surfaces with higher contents of oxygenated groups (Table 4), increased the ORR via two-electron transference to a higher extent than alkaline treatment. However, in the case of alkaline treatment, a possible modification of the physical structure, such as the specific surface area and the porosity of the substrate [29, 36, 37], could also contribute to the ORR toward $\mathrm{H}_{2} \mathrm{O}_{2}$ production.

The data related to the ORR for all studied materials were also analyzed using the Koutecky-Levich (K-L) equation; the results are displayed as K-L plots in Fig. 5, showing the results for all of the studied materials including $\mathrm{Pt} / \mathrm{C} \mathrm{E}$-TEK, which is the reference material for water production. The figure shows that the slopes are similar for all carbon materials, whereas a lower slope was found for the Pt/C E-TEK, which is the reference material for the four-electron transference in the ORR. The difference of the slopes between carbon materials and that of the Pt/C E-TEK is a clear indication that carbon materials follow a two-electron transference in the ORR.

Based on previous results [16], Pt/C E-TEK, the reference materials for the four-electron transference in the ORR, shows a slope of about $50(\mathrm{rpm})^{1 / 2}(\mathrm{~mA})^{-1}$ while Printex L6 and Vulcan XC 72R show a slope of about $110(\mathrm{rpm})^{1 / 2}(\mathrm{~mA})^{-1}$. Evaluating the results obtained in this paper by K-L plot, acidtreated Printex L6, alkaline-treated Printex L6, acid-treated Vulcan XC 72R, and alkaline-treated Vulcan XC 72R showed
Table 4 Percentage of functional groups on the surfaces of activated carbons determined by XPS

\begin{tabular}{llllll}
\hline Carbon support & $\mathrm{C}-\mathrm{C}$ aromatic & $\pi \rightarrow \pi^{*}$ & $\mathrm{CC}-\mathrm{H}$ aliphatic (\%) & $\mathrm{C}-\mathrm{O}$ and C=O & $\mathrm{COOH}$ \\
\hline Printex & 63.1 & 2.8 & 17.8 & 11.3 & 5.0 \\
Printex A & 19.7 & 0.4 & 50.1 & 18.7 & 11.1 \\
Printex B & 30.0 & 0.3 & 44.3 & 15.4 & 10.0 \\
Vulcan & 74.0 & 5.3 & 7.6 & 9.9 & 3.2 \\
Vulcan A & 33.1 & 0.6 & 42.0 & 15.1 & 9.2 \\
Vulcan B & 39.0 & 0.7 & 36.8 & 14.6 & 8.9 \\
\hline
\end{tabular}

$A$ acid-treated, $B$ base-treated 


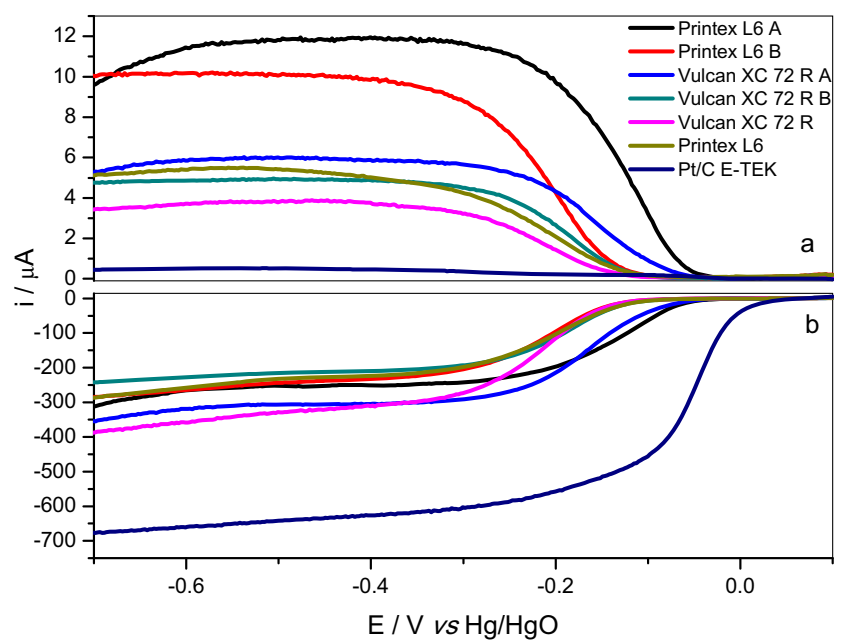

Fig. 4 Steady-state polarization curves for ORR using different carbon materials and Pt/C E-TEK in oxygen-saturated $1 \mathrm{~mol} \mathrm{~L}^{-1} \mathrm{NaOH}$ at a scan rate of $5 \mathrm{mV} \mathrm{s}^{-1}$. a Ring current $\mathrm{E}$ ring $=0.2 \mathrm{~V}$ and $\mathbf{b}$ Disk current at $1600 \mathrm{rpm}$

slope values of $116,96,95$, and $101(\mathrm{rpm})^{1 / 2}(\mathrm{~mA})^{-1}$, respectively. These slope values are much higher than those obtained for $\mathrm{Pt} / \mathrm{C}$, indicating a two-electron pathway in the ORR.

\section{Number of Electrons Transferred and Percentage of Hydrogen Peroxide}

Another way to elucidate the mechanism followed during the ORR for the studied materials is to calculate the number of electrons transferred and the relative formation rates of $\mathrm{H}_{2} \mathrm{O}$ and $\mathrm{H}_{2} \mathrm{O}_{2}$ during the ORR process, which can be determined quantitatively with a RRDE (rotating ring-disk electrode). Using the equation proposed by Demarconnay et al. [41] and by Jakobs et al. [42] (Eqs. 2-4), we calculated the percentages of $\mathrm{H}_{2} \mathrm{O}_{2}\left(p\left(\mathrm{H}_{2} \mathrm{O}_{2}\right)\right)$ and the number of electrons

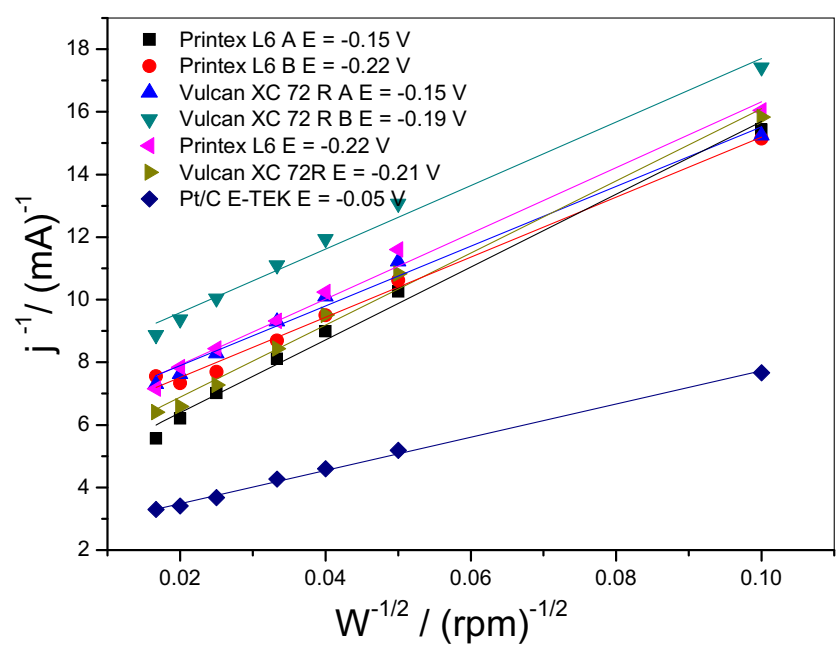

Fig. 5 Koutecky-Levich plots for all of the investigated carbon materials and for Pt/C E-TEK
Table 5 The $\mathrm{H}_{2} \mathrm{O}_{2}$ percentage produced and the number of electrons transferred during the ORR

\begin{tabular}{|c|c|c|c|c|c|c|}
\hline \multirow[t]{2}{*}{ Material } & \multicolumn{2}{|c|}{$E=-0.7 \mathrm{~V}$} & \multicolumn{2}{|c|}{$E=-0.6 \mathrm{~V}$} & \multicolumn{2}{|c|}{$E=-0.5 \mathrm{~V}$} \\
\hline & $n$ & $p\left(\mathrm{H}_{2} \mathrm{O}_{2}\right)$ & $n$ & $p\left(\mathrm{H}_{2} \mathrm{O}_{2}\right)$ & $n$ & $p\left(\mathrm{H}_{2} \mathrm{O}_{2}\right)$ \\
\hline Printex & 2.4 & 80 & 2.3 & 83 & 2.3 & 85 \\
\hline Printex A & 2.2 & 89 & 2.2 & 92 & 2.1 & 93 \\
\hline Printex B & 2.2 & 90 & 2.2 & 91 & 2.2 & 92 \\
\hline Vulcan & 2.8 & 59 & 2.7 & 65 & 2.6 & 68 \\
\hline Vulcan A & 2.5 & 76 & 2.4 & 81 & 2.4 & 82 \\
\hline Vulcan B & 2.4 & 82 & 2.3 & 83 & 2.3 & 85 \\
\hline
\end{tabular}

$A$ acid-treated, $B$ base-treated

transferred during the ORR using the data obtained from Fig. 1 at different potentials:

$p\left(\mathrm{H}_{2} \mathrm{O}\right)=\frac{N\left(-j_{\mathrm{D}} / j_{\mathrm{R}, 1}-j_{\mathrm{R}, 1}^{0}-1\right)}{N\left(-I_{D} / j_{\mathrm{R}, 1}-j_{\mathrm{R}, 1}^{0}+1\right)}$

$p\left(\mathrm{H}_{2} \mathrm{O}_{2}\right)=100-p\left(\mathrm{H}_{2} \mathrm{O}\right)$

$n_{t}=2\left[p\left(H_{2} \mathrm{O}\right)+1\right]$

where $N$ is the collection efficiency (in this case equal to 0.37 ), $J_{\mathrm{D}}$ is the disk current density at different potentials, $J_{\mathrm{R}, 1}$ is the limiting ring current density at different potentials, and $J_{0 \mathrm{R}, 1}$ is the limiting current density at a disk potential of $0.01 \mathrm{~V}$.

Table 5 shows the number of electrons transferred during the ORR and the calculated percentage of $\mathrm{H}_{2} \mathrm{O}_{2}$ produced at different applied potentials for each of the studied materials. The obtained results are in agreement with those of ring currents (Fig. 4) confirming that the ring current exhibited by the acid-treated Printex L6 at $-0.7 \mathrm{~V}$ is slightly lower than the current shown by the alkaline-treated Printex L6. Consequently, the percentage of $\mathrm{H}_{2} \mathrm{O}_{2}$ produced by the alkaline-treated Printex L6 is slightly higher (90\%) compared to that produced by the acid-treated Printex L6 (89\%). However, at -0.6 and $-0.5 \mathrm{~V}$, as shown in Fig. 4, the acid-treated Printex L6 exhibited the highest ring current resulting in the highest percentage of $\mathrm{H}_{2} \mathrm{O}_{2}$ production ( 92 and $93 \%$, respectively) and a transference of 2.2 and 2.1 electrons per $\mathrm{O}_{2}$ molecule at -0.6 and $-0.5 \mathrm{~V}$, respectively. In contrast, the untreated Vulcan XC $72 \mathrm{R}$, which showed the lowest ring current, exhibited the lowest percentage of $\mathrm{H}_{2} \mathrm{O}_{2}$ and transferred 2.8, 2.7, and 2.6

Table 6 Average values of contact angles ( \pm standard deviation)

\begin{tabular}{ll}
\hline Substrate & Contact angle $\left({ }^{\circ}\right)$ \\
\hline Printex L6 & $69.6 \pm 0.2$ \\
Basic-treated Printex L6 & $47.4 \pm 0.3$ \\
Acid-treated Printex L6 & $31.4 \pm 0.4$ \\
\hline
\end{tabular}




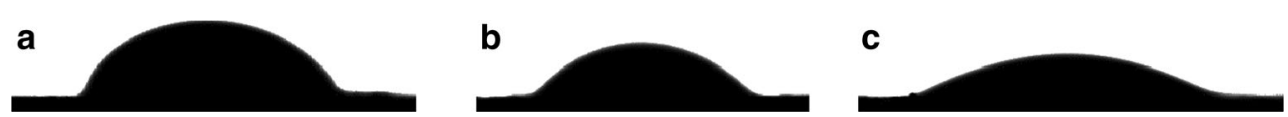

Fig. 6 Drops of ultra-pure water (produced by a Millipore Milli-Q device) on a substrate of a Printex L6 before the acid and basic treatments, $\mathbf{b}$ basictreated Printex L6, and c acid-treated Printex L6

electrons at $0.7,0.6$, and $0.5 \mathrm{~V}$, respectively. The other treated carbon samples exhibited intermediate ring current densities, $\mathrm{H}_{2} \mathrm{O}_{2}$ percentages, and number of transferred electrons as can be conferred from the results summarized in Table 3.

\section{Contact Angles of the Carbon Samples}

The average contact angles determined with the three tested surfaces are given in Table 6, for Printex Carbon L6.

It can be observed that the acid-treated Printex L6 showed the smallest contact angle $\left(31.4^{\circ}\right)$ indicating that this substrate presents higher hydrophilicity and consequently higher wettability (Fig. 6) than the other two Printex surfaces. When the same measurements were carried out for Vulcan XC 72R, there was also an increase in hydrophilicity (lower contact angles than on Printex L6, Printex L6 basic treated, and Printex L6 acid treated). However, not only the hydrophilicity is important to peroxide electrogeneration but also the surface area, porosity, and aliphatic chains. In the case of Printex L6 acid-treated catalyst, the surface area, porosity and functional oxygen-containing groups were higher than those measured for the best suitable material for peroxide electrogeneration using Vulcan XC 72R (acid treated). Regarding hydrophilicity, all the surfaces of Vulcan XC 72R present higher values when compared to all Printex L6 surfaces. This is because of the aliphatic chains which are more abundant on Printex L6 surfaces than on all Vulcan XC 72 R surfaces.

Probably, the presence of oxygenated acid species of the Printex L6 acid treated catalyst surface, verified by the XPS analyses, provides the principal contribution for its increased activity for peroxide electrogeneration, thus facilitating the formation of $\mathrm{H}_{2} \mathrm{O}_{2}$ [16]. However, the effects of area and porosity are also important. For Printex L6 acid treated catalyst, these parameters are higher than those found for Vulcan XC 72R surfaces. Although Vulcan XC 72R surfaces have higher hydrophilicities than Printex L6 surfaces, its higher area, porosity, and functional acid groups are more important to the catalytic activity of peroxide electrogeneration.

\section{Conclusions}

The obtained results for the local bonding structure and composition of carbon supports subjected to different treatments with respect to the ORR evidence that the acid treatment of Printex L6 leads to an increase in the oxygenated acid species, as confirmed by the Boehm methodology, and consequently to an increase in the catalytic activity of the two-electron transference in the ORR at potentials higher than $-0.7 \mathrm{~V}$. Considering that the alkaline-treated Printex L6 also resulted in the production of a large amount of $\mathrm{H}_{2} \mathrm{O}_{2}$, it is suggested that besides the modification of the chemical structure, physical changes of the substrate, including the specific surface area and the porosity, might contribute to the enhanced catalytic activity after alkaline and acid treatments. These morphological changes could also improve the activity of the material toward the ORR. Nevertheless, as the most suited material toward the two-electron pathway of the ORR, we identified the acid-treated Printex L6, which contains the highest concentration of carboxylic and hydroxyl species, responsible for the elevated $\mathrm{H}_{2} \mathrm{O}_{2}$ production.

Acknowledgments The authors wish to thank the Brazilian Funding Institutions CNPq (577292/2008-0, 150639/2013-9, 474913/2012-0, 406612/2013-7), CAPES and FAPESP (2005/59992-6, 2008/58789-0, 2009/09145-6, 2009/07859-1, 2010/04539-3, 2007/04759-0, 2011/21656-6), INCT Instituto Nacional de Ciência e Tecnologia (INCT) Energia e Meio Ambiente (Process Number: 573.783/2008-0), and UFABC for their financial support. We would like to thank Prof. Hugo Barbosa Suffredini from LEMN - CCNH - UFABC for the contact angle measurements.

\section{References}

1. S. Goeringer, N.R. de Tacconi, C.R. Chenthamarakshan, K. Rajeshwar, W.A. Wampler, Redox characterization of furnace carbon black surfaces. Carbon 39(4), 515-22 (2001)

2. J.A. Menéndez, E.M. Menéndez, M.J. Iglesias, A. García, J.J. Pis, Modification of the surface chemistry of active carbons by means of microwave-induced treatments. Carbon 37(7), 1115-21 (1999)

3. M. Gurrath, T. Kuretzky, H.P. Boehm, L.B. Okhlopkova, A.S. Lisitsyn, V.A. Likholobov, Palladium catalysts on activated carbon supports: influence of reduction temperature, origin of the support and pretreatments of the carbon surface. Carbon 38(8), 1241-55 (2000)

4. M.C. Román-Martínez, D. Cazorla-Amorós, A. Linares-Solano, C.S.-M. De Lecea, H. Yamashita, M. Anpo, Metal-support interaction in $\mathrm{Pt} / \mathrm{C}$ catalysts. Influence of the support surface chemistry and the metal precursor. Carbon 33(1), 3-13 (1995)

5. H.P. Boehm, Some aspects of the surface chemistry of carbon blacks and other carbons. Carbon 32(5), 759-69 (1994)

6. H. ShamsiJazeyi, T. Kaghazchi, Investigation of nitric acid treatment of activated carbon for enhanced aqueous mercury removal. J. Ind. Eng. Chem. 16(5), 852-8 (2010)

7. E. Antolini, Carbon supports for low-temperature fuel cell catalysts. Appl. Catal. B Environ. 88(1-2), 1-24 (2009)

8. L.-Y. Hsu, H. Teng, Influence of thermal treatment on the catalytic activity of $\mathrm{Cu}$-loaded carbons in $\mathrm{NO}$ reduction with $\mathrm{NH} 3$ and regeneration of the thermally deactivated catalysts. Appl. Catal. B Environ. 42(1), 69-76 (2003)

9. W. Xia, J. Masa, M. Bron, W. Schuhmann, M. Muhler, Highly active metal-free nitrogen-containing carbon catalysts for oxygen 
reduction synthesized by thermal treatment of polypyridine-carbon black mixtures. Electrochem. Commun. 13(6), 593-6 (2011)

10. H.-L. Chiang, C.P. Huang, P.C. Chiang, The surface characteristics of activated carbon as affected by ozone and alkaline treatment. Chemosphere 47(3), 257-65 (2002)

11. S. Dong Jin, P. Tae-Jin, I. Son-Ki, Effect of surface oxygen groups of carbon supports on the characteristics of $\mathrm{Pd} / \mathrm{C}$ catalysts. Carbon 31(3), 427-35 (1993)

12. Z. Qiang, J.-H. Chang, C.-P. Huang, Electrochemical generation of hydrogen peroxide from dissolved oxygen in acidic solutions. Water Res. 36(1), 85-94 (2002)

13. K.S. Yang, G. Mul, J.A. Moulijn, Electrochemical generation of hydrogen peroxide using surface area-enhanced Ti-mesh electrodes. Electrochim. Acta 52(22), 6304-9 (2007)

14. A. Alverez-Gallegos, D. Pletcher, The removal of low level organics via hydrogen peroxide formed in a reticulated vitreous carbon cathode cell. Part 2: the removal of phenols and related compounds from aqueous effluents. Electrochim. Acta 44(14), 2483-92 (1999)

15. S. Tang, G. Sun, J. Qi, S. Sun, J. Guo, Q. Xin et al., Review of new carbon materials as catalyst supports in direct alcohol fuel cells. Chin. J. Catal. 31(1), 12-7 (2010)

16. M.H.M.T. Assumpção, R.F.B. De Souza, D.C. Rascio, J.C.M. Silva, M.L. Calegaro, I. Gaubeur et al., A comparative study of the electrogeneration of hydrogen peroxide using Vulcan and Printex carbon supports. Carbon 49(8), 2842-51 (2011)

17. S. Marcotte, D. Villers, N. Guillet, L. Roué, J.P. Dodelet, Electroreduction of oxygen on Co-based catalysts: determination of the parameters affecting the two-electron transfer reaction in an acid medium. Electrochim. Acta 50(1), 179-88 (2004)

18. P. Vinke, M. van der Eijk, M. Verbree, A.F. Voskamp, H. van Bekkum, Modification of the surfaces of a gas-activated carbon and a chemically activated carbon with nitric acid, hypochlorite, and ammonia. Carbon 32(4), 675-86 (1994)

19. H.P. Boehm, Surface oxides on carbon and their analysis: a critical assessment. Carbon 40(2), 145-9 (2002)

20. A.M. Kalijadis, M.M. Vukčević, Z.M. Ovanović, Z.V. Laušević, M.D. Laušević. Characterization of surface oxygen groups on different carbon materials by the Boehm method and temperature programmed desorption. J.Serbian Chem. Soc. 76(5) (2011)

21. K. László, Adsorption from aqueous phenol and aniline solutions on activated carbons with different surface chemistry. Colloids Surf. A Physicochem. Eng. Asp. 265(1-3), 32-9 (2005)

22. V. Strelko Jr., D.J. Malik, Characterization and metal sorptive properties of oxidized active carbon. J. Colloid Interface Sci. 250(1), 213-20 (2002)

23. IdS Guimarães. Oxidação de carvões ativados de endocarpo de coco da Baía como soluções de HNO3 e uma investigação sobre o método de Boehm. Universidade Federal da Paraíba, Departamento de Química, Jão Pessoa, PB., p. 81 (2006)

24. U.A. Paulus, T.J. Schmidt, H.A. Gasteiger, R.J. Behm, Oxygen reduction on a high-surface area Pt/Vulcan carbon catalyst: a thinfilm rotating ring-disk electrode study. J. Electroanal. Chem. 495(2), 134-45 (2001)

25. E. Yeager, Electrocatalysts for $\mathrm{O} 2$ reduction. Electrochim. Acta 29(11), 1527-37 (1984)

26. R.R. Adzic. Recent advances in the Kinetics of oxygen reduction. Electrocatalysis 197-242 (1998)

27. M. Gindl, G. Sinn, W. Gindl, A. Reiterer, S. Tschegg, A comparison of different methods to calculate the surface free energy of wood using contact angle measurements. Colloids Surf. A Physicochem. Eng. Asp. 181(1-3), 279-87 (2001)

28. E. Papirer, J. Dentzer, S. Li, J.B. Donnet, Surface groups on nitric acid oxidized carbon black samples determined by chemical and thermodesorption analyses. Carbon 29(1), 69-72 (1991)

29. J.-W. Shim, S.-J. Park, S.-K. Ryu, Effect of modification with $\mathrm{HNO} 3$ and $\mathrm{NaOH}$ on metal adsorption by pitch-based activated carbon fibers. Carbon 39(11), 1635-42 (2001)

30. F. Rodríguez-reinoso, The role of carbon materials in heterogeneous catalysis. Carbon 36(3), 159-75 (1998)

31. M.H.M.T. Assumpção, A. Moraes, R.F.B. De Souza, I. Gaubeur, R.T.S. Oliveira, V.S. Antonin, et al. Low content cerium oxide nanoparticles on carbon for hydrogen peroxide electrosynthesis. Applied Catalysis A: General. (0)

32. M.H.M.T. Assumpção, A. Moraes, R.F.B. De Souza, M.L. Calegaro, M.R.V. Lanza, E.R. Leite et al., Influence of the preparation method and the support on $\mathrm{H} 2 \mathrm{O} 2$ electrogeneration using cerium oxide nanoparticles. Electrochim. Acta 111, 33943 (2013)

33. S.M. Senthil Kumar, J. Soler Herrero, S. Irusta, K. Scott, The effect of pretreatment of Vulcan XC-72R carbon on morphology and electrochemical oxygen reduction kinetics of supported Pd nanoparticle in acidic electrolyte. J. Electroanal. Chem. 647(2), 211-21 (2010)

34. B. Stöhr, H.P. Boehm, R. Schlögl, Enhancement of the catalytic activity of activated carbons in oxidation reactions by thermal treatment with ammonia or hydrogen cyanide and observation of a superoxide species as a possible intermediate. Carbon 29(6), 70720 (1991)

35. P. Chingombe, B. Saha, R.J. Wakeman, Surface modification and characterisation of a coal-based activated carbon. Carbon 43(15), 3132-43 (2005)

36. S.-J. Park, K.-D. Kim, Adsorption behaviors of $\mathrm{CO} 2$ and $\mathrm{NH} 3$ on chemically surface-treated activated carbons. J. Colloid Interface Sci. 212(1), 186-9 (1999)

37. M. Takaoka, H. Yokokawa, N. Takeda, The effect of treatment of activated carbon by $\mathrm{H} 2 \mathrm{O} 2$ or $\mathrm{HNO} 3$ on the decomposition of pentachlorobenzene. Appl. Catal. B Environ. 74(3-4), 179-86 (2007)

38. NIST X-ray Photoelectron Spectroscopy Database, AV. Naumkin, A. Kraut-Vass, S.W. Gaarenstroom, C.J. Powell, NIST Standard Reference Database 20 v. 4.1, et al.

39. A. Alvarez-Gallegos, D. Pletcher, The removal of low level organics via hydrogen peroxide formed in a reticulated vitreous carbon cathode cell, Part 1 . The electrosynthesis of hydrogen peroxide in aqueous acidic solutions. Electrochim. Acta 44(5), 853-61 (1998)

40. J. Vazquez-Arenas, D. Higgins, Z. Chen, M. Fowler, Z. Chen, Mechanistic analysis of highly active nitrogen-doped carbon nanotubes for the oxygen reduction reaction. J. Power Sources 205, 215-21 (2012)

41. L. Demarconnay, C. Coutanceau, J.M. Léger, Electroreduction of dioxygen (ORR) in alkaline medium on $\mathrm{Ag} / \mathrm{C}$ and $\mathrm{Pt} / \mathrm{C}$ nanostructured catalysts - effect of the presence of methanol. Electrochim. Acta 49(25), 4513-21 (2004)

42. R.C.M. Jakobs, L.J.J. Janssen, E. Barendrecht, Oxygen reduction at polypyrrole electrodes - I. Theory and evaluation of the rrde experiments. Electrochim. Acta 30(8), 1085-91 (1985) 